\title{
Influence of Different Types of Root Canal Irrigation Regimen on Resin-based Sealer Penetration and Pushout Bond Strength
}

Chundangaparambil Pushpahasan Sreedev ${ }^{1}$, Iswarya Raju ${ }^{1}$, Karthick Kumaravadivel ${ }^{2}$, Sebeena Mathew ${ }^{2}$, Boopathi Thangavel $^{2}$, Deepa Natesan Thangaraj ${ }^{2}$

1. Conservative Dentistry and Endodontics, MES Dental College, Malappuram, IND 2. Conservative Dentistry and Endodontics, KSR Institute of Dental Science and Research, Tiruchengode, IND

Corresponding author: Chundangaparambil Pushpahasan Sreedev, sreedevcp@gmail.com

\section{Abstract}

\section{Introduction}

The main objective of root canal treatment is to eliminate the micro-organism from the root canal system and three-dimensional obturation. The proper cleaning and shaping can be accomplished only by using appropriate instruments and effective irrigants during the root canal treatment.

\section{Aim}

To evaluate the influence of three different final irrigation regimen on depth of penetration of root canal sealers and push-out bond strength of obturation material.

\section{Materials and methods}

Thirty-six extracted single-rooted mandibular premolar human teeth with straight canals were decoronated and instrumented according to groups. Group I: Root canals were irrigated with 3\% sodium hypochlorite $(\mathrm{NaOCl})$, then irradiated with $980 \mathrm{~nm}$ diode laser $(\mathrm{n}=12)$, Group II: Root canals were irrigated with $3 \%$ $\mathrm{NaOCl}$, followed by $17 \%$ ethylenediaminetetraacetic acid (EDTA) $(n=12)$, Group III: Root canals were irrigated with $3 \% \mathrm{NaOCl}$, followed by $10 \%$ citric acid $(n=12)$. In each sample, single cone obturation was done with gutta-percha using AH plus sealer incorporated with rhodamine B dye. After seven days coronal, middle and apical thin cross sections were made for evaluation of dentinal tubule sealer penetration depth and pushout bond strength using confocal laser scanning microscope (CLSM) and universal testing machine, respectively. Statistical analysis among the three groups was done by using Kruskal-Wallis and post hoc test.

\section{Results}

Mean tubular penetration depth between diode laser $(136.57 \pm 48 \mu \mathrm{m})$, EDTA $(130.56 \pm 53 \mu \mathrm{m})$ and citric acid $(113.37 \pm 34 \mu \mathrm{m} ; \mathrm{P}<0.05)$ showed statistically highly significant results. Pushout bond strength did not

Received 04/07/2020 Review began 04/14/2020 Review ended 04/17/2020 Published 04/24/2020

\section{(c) Copyright 2020}

Sreedev et al. This is an open access article distributed under the terms of the Creative Commons Attribution License CC-BY 4.0., which permits unrestricted use, distribution, and reproduction in any medium, provided the original author and source are credited. differ significantly between diode laser $(1.21 \pm 0.48 \mathrm{Mpa})$, EDTA $(1.05 \pm 0.45 \mathrm{Mpa})$ and citric acid $(0.93 \pm 0.44$ Mpa; $\mathrm{P}>0.05)$.

\section{Conclusion}

Mean tubular penetration depth of AH plus sealer was better in diode laser than in EDTA and citric acid. Average push-out bond strength of obturation material did not differ significantly between diode laser, EDTA and citric acid.

Categories: Medical Physics, Healthcare Technology, Dentistry

Keywords: citric acid, diode laser, edta, endodontic irrigants, root canal sealers

\section{Introduction}

The purposes of root canal treatments are to eliminate microorganisms from the root canal system and to prevent re-contamination. Because of the complex anatomy of the root canal system, it is impossible to achieve complete disinfection of the root canal using instrumentation alone. Irrigation is an important compliment to instrumentation because it removes or wash out bacteria, debris, and necrotic tissue present inside the canal [1].

The smear layer consists of organic and inorganic components, such as vital or necrotic pulp tissue, microorganisms, salivary components, blood cells, and dentinal debris. It has an amorphous and irregular appearance and consists of two separate layers [2]. The removal of the smear layer is still a matter of debate. In contrast, some experts believe that the smear layer should be removed from the surface of the canal wall because it can not only harbour bacteria but also reduce dentin permeability by preventing penetration of 
root canal sealers into the dentinal tubules. Thus it can act as a barrier between the obturating materials and root canal wall that may interfere with the formation of an appropriate seal [3-6].

Sodium hypochlorite $(\mathrm{NaOCl})$ is the most common irrigant used during root canal therapy. But it has weak action towards the removal of inorganic part of the smear layer.

Chelating agents, such as ethylenediaminetetraacetic acid (EDTA), citric acid (CA), maleic acid (MA), phosphoric acid, and combinations of EDTA and $\mathrm{NaOCl}$ have been used to remove the smear layer [7].

Diode lasers emitting at $980 \mathrm{~nm}$ have better research and clinical applications because they transmit energy through thin flexible fibers that are compatible with the morphology and curved shapes of root canals. Diode lasers have a good penetration potential, with high absorption peaks for melanin and hemoglobin and limited interactions with water and hydroxyapatite [8]. Its power output ranges from 0.5 to $7 \mathrm{~W}$ and can be used with different operating modes like continuous wave, pulsed power and chopped mode [9]. Wang et al. demonstrated the effect of $980-\mathrm{nm}$ wavelength diode laser on removal of smear layer and debris and degree of apical leakage in obturated teeth [10]. Certain studies found that citric acid of variable concentrations cleansed the canal walls and left the dentinal tubules open, which allowed intimate adaptation of resinbased materials. This may help in more adaptation of epoxy resin-based sealers to root canal walls [11].

Sealer penetration into the dentinal tubules is a desirable property, because it would entomb residual debris and microorganisms and it can maintain them far from nutrient sources. Moreover, deep endodontic sealer penetration is notably important because it decreases the interface between gutta-percha and root dentin and it may improve the retention of the filling mass by mechanical locking [12].

Bond strength testing is the best measure of adhesion. Adhesion of the root canal filling to the dentinal walls is advantageous in eliminating any space between the filling and the canal wall and also resists dislodgement of the filling during subsequent manipulation [13].

Several studies have investigated the degree and adaptation of root canal sealers to root dentin [3-6]. However, limited studies have investigated the influence of final irrigation regimen on depth of penetration of root canal sealers and push out bond strength of obturation material.

The aims of the present study were to compare the effect of diode laser, 17\% EDTA and 10\% citric acid on penetrability of a resin-based sealer into dentinal tubules using a confocal laser scanning microscope (CLSM) and push-out bond strength of gutta-percha. The null hypotheses tested were that the different irrigation regimen has no difference in sealer penetrability and push-out bond strength.

\section{Materials And Methods Tooth preparation}

The present in vitro study was approved by the Ethical Committee from the KSR Institute of Dental Science and Research (Ref: 079/KSRIDSR/EC/2014). The study was conducted in the Department of Conservative Dentistry and Endodontics, KSR Institute of Dental Science and Research, Thiruchengode, Tamil Nadu. Sample size was calculated using online sample size calculator (Raosoft.Inc.). The power of the study was set at $80 \%$. Thirty-six extracted non-carious single-rooted mandibular premolar human teeth with straight canals were used in this study. Before the experiment, root surfaces of all specimens were cleaned mechanically and ultrasonically. The crowns of the teeth were decoronated at the cemento-enamel junction with a high-speed diamond wafering blade (Struers Ltd, Mumbai) having $300 \mu \mathrm{m}$-thickness and $160 \mathrm{~mm}$ diameter under water irrigation. The canals were cleaned and instrumented by the crown-down technique up to ProTaper F3 (Dentsply Maillefer, Ballaigues, Switzerland). The working length was visually determined 1 $\mathrm{mm}$ shorter from the anatomical apical foramen. Total number of samples were randomly divided into three groups $(n=12)$ based on the irrigation regimen.

Group I: Root canals were irrigated with 3\% $\mathrm{NaOCl}$ (Neelkanth Healthcare, Boranada, India) for 2 min, then irradiated with $980 \mathrm{~nm}$ diode laser (SIROlaser 2.2; SIRONA Dental, Bensheim, Germany) in two cycles of 7 seconds with $5 \mathrm{~W}$ power in the continuous mode in a whirling motion from apical to coronal portion of root canal using a 200- $\mu \mathrm{m}$ diameter flexible optical fiber. Sodium hypochlorite irrigation was done in between and after laser irradiation. Group II: Root canals were irrigated with 3\% NaOCl for 2 min, followed by $17 \%$ EDTA (Fisher Scientific, Mumbai, India) for 1 min. Group III: Root canals were irrigated with 3\% NaOCl for 2 min, followed by $10 \%$ citric acid (Freshly prepared) for $1 \mathrm{~min}$. Final irrigation and in between two active irrigants of all groups were done with $5 \mathrm{ml}$ of normal saline to terminate any solvent action of the irrigants and to remove any precipitates that may have formed from the irrigants. The root canals were dried with paper points. The teeth were then randomly divided into three groups of 12 teeth each.

Equal parts of paste A and paste B of an epoxy resin-based sealer (AH Plus, Dentsply Maillefer) were mixed with $0.1 \%$ rhodamine B (RITC; Sigma-Aldrich, St. Louis, MO). The endodontic sealer was applied in the canal 1-mm shorter than the WL using ProTaper F3 gutta-percha cone (Dentsply Maillefer) and single cone 
obturation was done. The specimens were stored at $37^{\circ} \mathrm{C}$ and $100 \%$ humidity for seven days to allow the sealer to set. A 1-mm thick horizontal slice was prepared from coronal middle and apical portion of the root using a diamond disc (Diamond Disc Superflex 910S/220, Italy) under water cooling and apical 3 mm was discarded. The coronal surfaces of the slices were polished with Arotec paste (Arotec, Cotia, SP, Brazil) to eliminate dentin debris generated during the cutting procedures and to produce a highly reflective surface.

\section{Sealer penetration}

All the slices were examined using an Olympus Fluoview 1000 confocal laser scanning microscope (CLSM) (Olympus Corporation, Tokyo, Japan) with $40 \times$ magnification. The image settings were $70-\mu \mathrm{m}$ depth with $800 \times 800$ pixels. Four images from different area of each section were taken and maximum penetration depth of the sealer in each image was measured in micrometers. Mean depth for each section is calculated. Images were captured with the HCX PL APO 40/1.25-0.75 oil lens (Leica), and acquired with the IM50 Image Manager Software, v1.20 (Leica Microsystems, Buffalo Grove, IL, USA) (Figure 1). When penetration was observed, the length of the sealer tag from the canal wall along the entire tubule was recorded in microns. The canal wall served as the starting point, and sealer penetration into dentinal tubules (sealer tags) was calculated to a maximum depth of $1000 \mu \mathrm{m}$ with the ruler tool of the Leica Application Suite Advanced Fluorescence Lite software (Leica Microsystems).

\section{Push-out bond strength}

After the sealer penetration examination, the root slices were prepared for push-out bond strength test. The thickness of the root slices was measured using a vernier caliper, the filling material was then loaded with a 0.5-mm diameter cylindrical stainless steel plunger. Loading was applied on a universal testing machine (Z050, Zwick/Roell, Ulm, Germany) at a speed of $0.5 \mathrm{~mm} / \mathrm{min}$ in an apical coronal direction to avoid any interference because of the root canal taper during push-out testing. The bond strength was determined using a computer software program connected to the universal testing machine.

The maximum load applied to the filling material before debonding was recorded in Newtons.

The load at failure recorded in Newtons $(\mathrm{N})$ was divided by the interfacial area to express the bond strength in megapascals (MPa).

Push-out bond strength $(\mathrm{MPa})=$ Maximum load $(\mathrm{N}) /$ Adhesion area of root canal filling $\left(\mathrm{mm}^{2}\right)$. The "bonded (adhesion) area' of each slice was calculated using the formula below: $2 \pi r h$, where ' $\pi$ ' is equal to 3.14 , ' $r$ ' is the radius of root canal filling and ' $h$ ' is the thickness of the slice. Coronal and apical radius of filling material assumed to be the same $(1 \mathrm{~mm})$. After the bond strength test was performed, both sides of the root slices were examined under a light microscope at $25 \times$ magnification to determine the failure mode. Modes of bond failure were considered as follows: (1) adhesive; at filling material-dentin interface, (2) cohesive; within filling material, and (3) mixed failure.

\section{Results}

Both push-out bond strength and tubule penetration data were statistically analyzed by using Kruskal-Wallis and post hoc test (STATISTICA 7.0, StatSoft Inc., Tulsa, OK, USA). The level of significance was set at $\mathrm{p}<$ 0.05. Table 1 shows the statistical result of depth of dentinal tubular sealer penetration in the test groups. Diode laser $(136.57 \pm 48 \mu \mathrm{m})$ group showed the highest sealer penetration into dentinal tubules than EDTA group $(130.56 \pm 53 \mu \mathrm{m})$ and citric acid group $(113.37 \pm 34 \mu \mathrm{m})(\mathrm{p}<0.05)$. Coronal third showed higher depth of sealer penetration and apical third with lower depth of sealer penetration into dentinal tubules (Figure 1).

\section{Root canal third}

Coronal

Middle

Apical

Median

\section{Root canal filling materials}

Diode laser

$185.16 \pm 43.43$

$131.30 \pm 22.02$

$93.25 \pm 21.22$

129.35

\section{EDTA}

$179.07 \pm 56.43$

$126.48 \pm 23.68$

$86.14 \pm 20.05$

120.45

\section{Citric acid}

$139.02 \pm 35.30$

117.54 + 15.32

$83.53 \pm 19.57$

110.00

TABLE 1: Dentinal tubule penetration depth $(\mu \mathrm{m})$ in various test groups $(p<0.05)$. 


\section{Cureus}
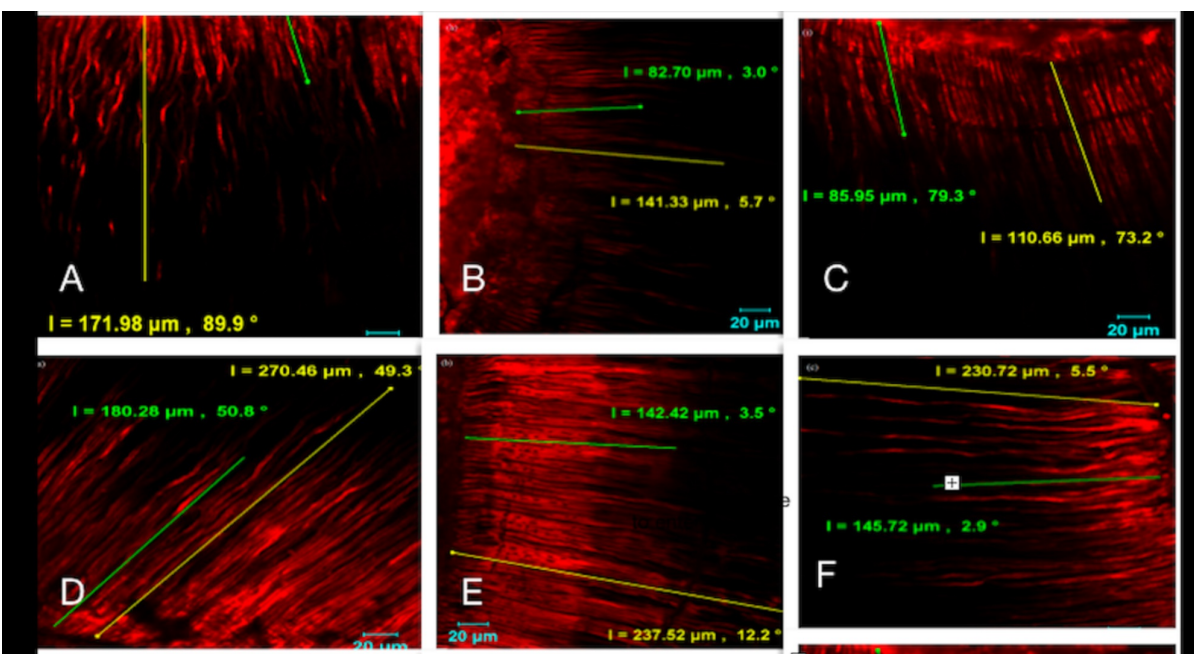

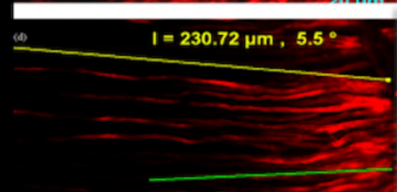

$I=145.72 \mu \mathrm{m}, 2.9^{\circ}$

G

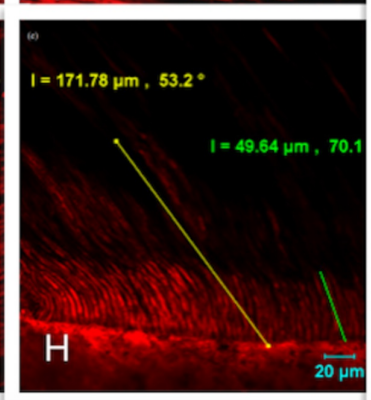

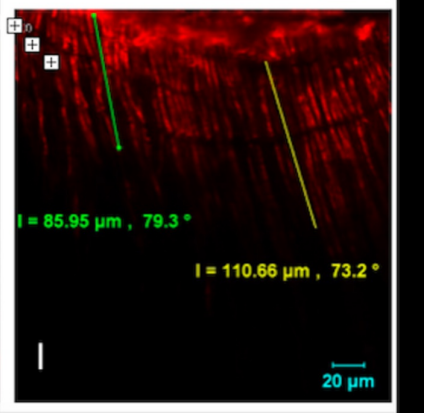

$20 \mu$

FIGURE 1: Confocal microscopic image showing the penetration of different groups.

(A) Citric acid coronal, (B) Citric acid middle, (C) Citric acid apical, (D) Diode coronal, (E) Diode middle, (F) Diode apical, (G) EDTA coronal, (H) EDTA middle, (I) EDTA apical.

EDTA: Ethylenediaminetetraacetic acid

No significant difference was found amongst the bond strength values of the test groups. Citric acid group $(0.93 \pm 0.44 \mathrm{MPa})$ showed lower bond strength values than diode laser $(1.21 \pm 0.48 \mathrm{MPa})$ and EDTA group $(1.05 \pm 0.45 \mathrm{MPa})$. Diode laser group showed higher bond strength. Comparison of bond strength in root canal thirds showed coronal third with higher bond strength and apical third with lower bond strength. Table 2 shows the statistical result of push-out bond strength of the test groups. Stereomicroscopic failure analysis is illustrated in Table 3. The predominant failure mode was mixed failure in diode laser and EDTA group whereas in citric acid group more adhesive failures were found.

\begin{tabular}{|c|c|c|c|}
\hline \multirow{2}{*}{ Root canal third } & \multicolumn{3}{|c|}{ Root canal filling materials } \\
\hline & Diode laser & EDTA & Citric acid \\
\hline Coronal & $1.41 \pm 0.51$ & $1.22 \pm 0.46$ & $1.10 \pm 0.42$ \\
\hline Middle & $1.22 \pm 0.46$ & $1.02 \pm 0.47$ & $0.89 \pm 0.45$ \\
\hline Apical & $1.02 \pm 0.42$ & $0.92 \pm 0.42$ & $0.80 \pm 0.42$ \\
\hline Median & 1.21 & 1 & 0.99 \\
\hline
\end{tabular}

TABLE 2: Bond strength mean values and standard deviations (in $\mathrm{MPa}$ ) for filling material displacement from intraradicular dentine in each third using the push-out test in specimens $(p<$ 0.05). 


\begin{tabular}{|c|c|c|c|c|c|c|c|c|c|}
\hline \multirow{2}{*}{ Failure mode } & \multicolumn{3}{|c|}{ Diode laser } & \multicolumn{3}{|c|}{ EDTA } & \multicolumn{3}{|c|}{ Citric acid } \\
\hline & CT & MT & AT & CT & MT & AT & CT & MT & AT \\
\hline Adhesive & 30 & 20 & 20 & 30 & 30 & 40 & 40 & 30 & 30 \\
\hline Cohesive & 30 & 30 & 20 & 40 & 30 & 20 & 10 & 30 & 20 \\
\hline Mixed & 40 & 50 & 60 & 30 & 40 & 40 & 50 & 40 & 50 \\
\hline
\end{tabular}

TABLE 3: Stereo microscopic evaluation of failure mode after push-out bond strength.

CT: Cervical third; MT: Middle third; AT: Apical third.

\section{Discussion}

The presence of a smear layer on the canal walls can reduce dentin permeability and may hinder penetration of sealers into dentinal tubules [14]. Therefore, to improve the quality of the root canal filling its removal is essential, as the three different root canal irrigation regimens affect the bond strength and sealer penetration variably on the same epoxy resin-based sealer. The null hypothesis that there is no difference among the groups tested was rejected. The integrity of sealer penetration using single master cone technique is comparable to that of cold lateral compaction, and Thermafil technique [15]. Sealer penetration into the dentinal tubules could improve sealing of a root filling by increasing the surface contact area between the root filling materials and dentinal walls [16]. Furthermore, retention of root filling material might be improved by mechanical locking.

CLSM was used for evaluation of the dentinal tubule penetrations instead of scanning electron microscope because it helps to create standard and reproducible three-dimensional imaging of the samples without damaging them [17]. It also allows evaluation of tubule penetration and adaptation of sealer quickly and objectively in a panoramic image manner obtained at a lower magnification through the fluorescent effect of rhodamine B. It has been previously shown that rhodamine B is a safe dye that has no effect on the setting of sealers [18].

The results of this study showed that the maximum penetration of all the resin sealers was seen at the coronal third, followed by the middle third and least in the apical third. Various authors have demonstrated regional variation in the depth of tubular penetration. The apical dentin displays less tubule density, with some areas completely devoid of tubules [19]. According to some experts, it is harder to remove the smear layer from the apical third than from the other thirds. At this third, the delivery of the irrigant is minimized and dentin showed less tubule density or even areas with absent of tubules [20]. Modified organic matrix layer with an amorphous form and tubule visibility were seen at low power whereas sparse lava-like formations with opened tubules were seen at higher power. These altered root canal micro changes could be dissolved by $\mathrm{NaOCl}$ which may facilitate the better sealer penetration [21].

Irradiation of Nd:YAG laser in root canals negatively influenced the adaptation of hydrophilic resin-based sealers to the dentin walls, and sealer penetration into the dentinal tubules. The wavelengths of these lasers caused the melting and resolidification of dentin, which might have led to occlusion of dentinal tubules and it was the reason for impaired permeability of canal walls [22]. However, in the present study diode lasers caused ablation of dentin and thus exposing the dentinal tubules. This phenomenon causes an increase in dentin permeability. These lasers also promoted the loss of dentin hydration and thus improving the sealing capacity of this sealer. Root canal walls also exhibited modified smear layer and some cracks. The choice for the power setting and duration used in the present study was based on the results of Wang et al., who demonstrated that these parameters yielded a temperature rise of almost $8.1^{\circ} \mathrm{C}$, which does not exceed the threshold supported by the periapical tissues without causing thermal damage [10,23].

It is difficult to completely remove the residual smear layer to allow sealer penetration, particularly in the apical third of the root, because the smaller size of the apical third compared with the other thirds impedes the circulation and impaired action of the irrigating solutions. In addition, there are fewer dentinal tubules due to increased tubular sclerosis. Acoustic and hydrodynamic properties of irrigants also might have improved the effectiveness of irrigating solutions in the apical region [18]; agitation with a laser has been used in endodontic therapy to reduce the number of bacteria and to modify the surface of the root canal [24]. Surface tension and its viscosity are two of the most essential parameters related to fluid flow. Wettability plays a major role for obtaining better contact time of irrigants in root canal walls. Surface tension is a phenomenon of intramolecular attraction, and this can be accomplished by the addition of surfactant or raising temperature [25]. Few studies showed the improved action of endodontic irrigants by raising temperatures and adding surfactants. However, such alterations were not considered in the present study [26]. 
Photon-induced photoacoustic streaming (PIPS) is a laser-activated irrigation technique that cannot completely remove bacteria from infected root canal dentinal tubules but can generate less infection and removes biofilm better than passive ultrasonic irrigation technique [27]. Advanced noninvasive lightactivated disinfection (ANILAD) is a more efficient type of light-activated disinfection that shows the better penetration into dentinal tubules and the bacterial kill rate [28].

The push-out test has been used to evaluate the dentin bond strength of root canal filling materials. This method allows the standardization of the specimens and evaluation of very low bond strength values. For allowing the assessment of bond strength at different root levels, we obtained root horizontal sections from each third of the roots and plunger kept to a tip size of $0.5 \mathrm{~mm}$ to prevent the touching the dentin walls during the test. It has also previously been shown that the location of the slice might not have a significant effect on bond strength.

Some studies used only the sealer for filling the root canal to eliminate the influence of the two interfaces in the push-out test. It could eliminate the influence of gutta-percha in adhesion test. Also as a cylindrical plunger was used, the irregular shape of root canals can influence the results [24,29].

When smear layer was removed, the highest adhesive force values associated with epoxy resin-based sealers occurred with a final flush of $\mathrm{NaOCl}$. Epoxy resin-based AH Plus showed better penetration into microirregularities due to its creep capacity and long setting time, which might increase the mechanical interlocking between sealer and root dentine. In addition, cohesion amongst sealer molecules, which increases its resistance to removal and/or displacement from dentine, contributes to the greater bond strength [30].

\section{Conclusions}

Within the limitations, this in vitro study concluded that the diode laser is useful for better root canal sealer penetration and provides higher push-out bond strength than EDTA, citric acid and can be considered for the clinical root canal treatment procedures. The maximum sealer penetration was achieved in coronal third. The sealer penetration was least in the apical third area.

\section{Additional Information \\ Disclosures}

Human subjects: All authors have confirmed that this study did not involve human participants or tissue. Animal subjects: All authors have confirmed that this study did not involve animal subjects or tissue. Conflicts of interest: In compliance with the ICMJE uniform disclosure form, all authors declare the following: Payment/services info: All authors have declared that no financial support was received from any organization for the submitted work. Financial relationships: All authors have declared that they have no financial relationships at present or within the previous three years with any organizations that might have an interest in the submitted work. Other relationships: All authors have declared that there are no other relationships or activities that could appear to have influenced the submitted work.

\section{References}

1. Tuncer AK, Tuncer S: Effect of different final irrigation solutions on dentinal tubule penetration depth and percentage of root canal sealer. J Endod. 2012, 38:860-863. 10.1016/j.joen.2012.03.008

2. Czonstkowsky M, Wilson EG, Holstein FA: The smear layer in endodontics . Dent Clin North Am. 1990, 34:13-25.

3. Lester KS, Boyde A: Scanning electron microscopy of instrumented, irrigated and filled root canals . Br Dent J. 1977, 143:359-367. 10.1038/sj.bdj.4804007

4. White RR, Goldman M, Lin PS: The influence of the smeared layer upon dentinal tubule penetration by plastic filling materials. J Endod. 1984, 10:558-562. 10.1016/S0099-2399(84)80100-4

5. Cergneux M, Ciucchi B, Dietschi JM, Holz J: The influence of the smear layer on the sealing ability of canal obturation. Int Endod J. 1987, 20:228-232. 10.1111/j.1365-2591.1987.tb00619.x

6. Da Costa Lima GA, Aguiar CM, Câmara AC, Alves LC, dos Santos FA, do Nascimento AE: Comparison of smear layer removal using the Nd:YAG laser, ultrasound, ProTaper universal system, and CanalBrush methods: an in vitro study. J Endod. 2015, 41:400-404. 10.1016/j.joen.2014.11.004

7. Aranda-Garcia AJ, Kuga MC, Chavéz-Andrade GM, et al.: Effect of final irrigation protocols on microhardness and erosion of root canal dentin. Microsc Res Tech. 2013, 76:1079-1083. 10.1002/jemt.22268

8. Gutknecht N, Franzen R, Schippers M, Lampert F: Bactericidal effect of a 980-nm diode laser in the root canal wall dentin of bovine teeth. J Clin Laser Med Surg. 2004, 22:9-13. 10.1089/104454704773660912

9. Moritz A, Gutknecht N, Goharkhay K, Schoop U, Wernisch J, Sperr W: In vitro irradiation of infected root canals with a diode laser: results of microbiological, infrared spectrometric, and stain penetration examinations. Quintessence Int. 1997, 28:205-209.

10. Wang X, Sun Y, Kimura Y, Kinoshita J, Ishizaki NT, Matsumoto K: Effects of diode laser irradiation on smear layer removal from root canal walls and apical leakage after obturation. Photom Laser Surg. 2005, 23:575581. 10.1089/pho.2005.23.575

11. Smith JJ, Wayman BE: An evaluation of the antimicrobial effectiveness of citric acid as a root canal irrigant . J Endod. 1986, 12:54-58. 10.1016/S0099-2399(86)80128-5 
12. Ordinola-Zapata R, Bramante CM, Graeff MS, et al.: Depth and percentage of penetration of endodontic sealers into dentinal tubules after root canal obturation using a lateral compaction technique: a confocal laser scanning microscopy study. Oral Surg Oral Med Oral Pathol Oral Radiol Endod. 2009, 108:450-457. 10.1016/j.tripleo.2009.04.024

13. Rahimi M, Jainaen A, Parashos P, Messer HH: Bonding of resin-based sealers to root dentin . J Endod. 2009, 35:121-124. 10.1016/j.joen.2008.10.009

14. Kokkas AB, Boutsioukis AC, Vassiliadis LP, Stavrianos CK: The influence of the smear layer on dentinal tubule penetration depth by three different root canal sealers: an in vitro study. J Endod. 2004, 30:100-102. 10.1097/00004770-200402000-00009

15. Saatchi M, Barekatain B, Behzadian M: Comparing the apical microleakage of lateral condensation and chloroform dip techniques with a new obturation method. Dent Res J. 2011, 8:22-27.

16. Calt S, Serper A: Dentinal tubule penetration of root canal sealers after root canal dressing with calcium hydroxide. J Endod. 1999, 25:431-433. 10.1016/S0099-2399(99)80273-8

17. Jardine AP, Rosa RA, Santini MF, et al.: The effect of final irrigation on the penetrability of an epoxy resinbased sealer into dentinal tubules: a confocal microscopy study. Clin Oral Investig. 2016, 20:117-123. 10.1007/s00784-015-1474-8

18. Sungur DD, Purali N, Coşgun E, Calt S: Push-out bond strength and dentinal tubule penetration of different root canal sealers used with coated core materials. Restor Dent Endod. 2016, 41:114-120. 10.5395/rde.2016.41.2.114

19. Chandra SS, Shankar P, Indira R: Depth of penetration of four resin sealers into radicular dentinal tubules: a confocal microscopic study. J Endod. 2012, 38:1412-1416. 10.1016/j.joen.2012.05.017

20. De-Deus G, Accorsi-Mendonca T, de Carvalho e Silva L, Leite CA, da Silva D, Moreira EJ: Self-adjusting file cleaning-shaping-irrigation system improves root-filling bond strength. J Endod. 2013, 39:254-257. 10.1016/j.joen.2012.10.026

21. Marchesan MA, Brugnera-Junior A, Ozorio JE, Pécora JD, Sousa-Neto MD: Effect of 980-nanometer diode laser on root canal permeability after dentin treatment with different chemical solutions. J Endod. 2008, 34:721-724. 10.1016/j.joen.2008.02.020

22. Moura-Netto C, Mello-Moura AC, Palo RM, Prokopowitsch I, Pameijer CH, Marques MM: Adaptation and penetration of resin-based root canal sealers in root canals irradiated with high-intensity lasers. J Biomed Opt. 2015, 20:038002. 10.1117/1.JBO.20.3.038002

23. Arslan H, Ayrancı LB, Karatas E, Topçuoğlu HS, Yavuz MS, Kesim B: Effect of agitation of EDTA with 808nanometer diode laser on removal of smear layer. J Endod. 2013, 39:1589-1592. 10.1016/j.joen.2013.07.016

24. Fisher MA, Berzins DW, Bahcall JK: An in vitro comparison of bond-strength of various obturation materials to root canal dentin using a push-out test design. J Endod. 2007, 33:856-858. 10.1016/j.joen.2007.02.011

25. Bukiet F, Soler T, Guivarch M, Camps J, Tassery H, Cuisinier F, Candoni N: Factors affecting the viscosity of sodium hypochlorite and their effect on irrigant flow. Int Endod J. 2013, 46:954-961. 10.1111/iej.12086

26. Poggio C, Ceci M, Beltrami R, Colombo M, Dagna A: Viscosity of endodontic irrigants: influence of temperature. Dent Res J. 2015, 12:425-430. 10.4103/1735-3327.166189

27. Peters OA, Bardsley S, Fong J, Pandher G, Divito E: Disinfection of root canals with photon-initiated photoacoustic streaming. J Endod. 2011, 37:1008-1012. 10.1016/j.joen.2011.03.016

28. Lim Z, Cheng JL, Lim TW, Teo EG, Wong J, George S, Kishen A: Light-activated disinfection: an alternative endodontic disinfection strategy. Aust Dent J. 2009, 54:108-114. 10.1111/j.1834-7819.2009.01102.x

29. Economides N, Gogos C, Kodonas K, Beltes C, Kolokouris I: An ex vivo comparison of the push-out bond strength of a new endodontic filling system (Smartseal) and various gutta-percha filling techniques. Odontology. 2012, 100:187-191. 10.1007/s10266-011-0040-3

30. Neelakantan P, Varughese AA, Sharma S, Subbarao CV, Zehnder M, De-Deus G: Continuous chelation irrigation improves the adhesion of epoxy resin-based root canal sealer to root dentine. Int Endod J. 2012, 45:1097-1102. 10.1111/j.1365-2591.2012.02073.x 